\title{
Avaliação de mutagenicidade e antimutagenicidade de diferentes frações de Pterogyne nitens (Leguminosae), utilizando ensaio de micronúcleo em Tradescantia pallida
}

\author{
Fernanda G. Ferreira, ${ }^{1}$ Luis O. Regasini, ${ }^{2}$ Aline M. de Oliveira, ${ }^{1}$ Juliana A. D. B. Campos, ${ }^{3}$ \\ Dulce H. S. Silva, ${ }^{2}$ Alberto J. Cavalheiro, ${ }^{2}$ Raquel A. dos Santos, ${ }^{4}$ Carmen L. Bassi, ${ }^{5}$ \\ Vanderlan da S. Bolzani, ${ }^{2}$ Christiane P. Soares $*, 1$ \\ ${ }^{1}$ Departamento de Análises Clínicas, Faculdade de Ciências Farmacêuticas, Universidade Estadual Paulista, \\ 14801-902 Araraquara-SP, Brasil, \\ ${ }^{2} N u B B E$ - Núcleo de Bioensaios, Biossíntese e Ecofisiologia de Produtos Naturais, Instituto de Química, \\ Universidade Estadual Paulista, 14800-900 Araraquara-SP, Brasil, \\ ${ }^{3}$ Departamento de Odontologia Social, Faculdade de Odontologia, Universidade Estadual Paulista, 14801-90 \\ Araraquara-SP, Brasil, \\ ${ }^{4}$ Departamento de Genética, Faculdade de Medicina de Ribeirão Preto, Universidade de São Paulo, 14040-900 \\ Ribeirão Preto-SP, Brasil, \\ ${ }^{5}$ Departamento de Genética, Faculdade de Ciências Médicas, Universidade Federal do Mato Grosso, 78060-900 \\ Cuiabá-MT, Brasil
}

\begin{abstract}
RESUMO: Pterogyne nitens (Fabaceae-Caesalpinioideae) é uma árvore nativa da América do Sul, onde é empregada na medicina popular para o tratamento da ascaridíase. Recentemente, descrevemos o efeito mutagênico do extrato etanólico das folhas de P. nitens. Dessa forma, o presente estudo teve por objetivo aprofundar a avaliação do potencial mutagênico das frações isoladas das folhas de Pterogyne nitens, acetato de etila (AcOEt), n-butanólica (BuOH) e hidroalcóolica (HA). Quando o efeito mutagênico foi observado somente nas maiores concentrações testadas, o potencial antimutagênico também foi avaliado. Os ensaios mutagênicos e antimutagênicos foram realizados utilizando ensaio de micronúcleo em Trandescantia pallida. $\mathrm{Na}$ avaliação de mutagenicidade, observou-se o efeito nas frações AcOEt $(0,460 \mathrm{mg} / \mathrm{mL}), \mathrm{BuOH}$ $(0,142,0,285,0,570$ e $1,14 \mathrm{mg} / \mathrm{mL})$ e HA $(0,050,0,100,0,200$ e $0,400 \mathrm{mg} / \mathrm{mL})$. Considerando que o efeito mutagênico da fração AcOEt foi observado somente na concentração mais elevada $(0,460 \mathrm{mg} / \mathrm{mL})$, o potencial antimutagênico da mesma foi avaliado. As concentrações de $0,115 \mathrm{e}$ $0,230 \mathrm{mg} / \mathrm{mL}$ da fração AcOEt demonstraram atividade antimutagênica. A partir dos resultados do presente estudo, conclui-se que determinadas frações de $P$. nitens apresentam mutagenicidade (BuOH e HA), enquanto a fração AcOEt apresentou efeito antimutagênico nas maiores concentrações. Esses resultados tornam o estudo da $P$. nitens bastante promissor, considerando que esta planta possui distribuição geográfica ampla e tem sido pouco estudada.
\end{abstract}

Unitermos: Pterogyne nitens, Leguminosae, mutagenicidade, antimutagenicidade, Tradescantia pallida.

\begin{abstract}
Evaluation of mutagenicity and antimutagenicity of different fractions of Pterogyne nitens (Leguminosae), using Tradescantia pallida micronuclei assay". Pterogyne nitens (Fabaceae-Caesalpinioideae) is a tree native to South American, where it is used in folk treatment of ascaridiasis. Recently, we have been describing the mutagenic effect of the ethanol extract of leaves of $P$. nitens. Thus, the present study aimed at evaluating the mutagenic potential of the ethyl acetate (EtOAc), $n$ - butanol $(\mathrm{BuOH})$ and hydroalcoholic $(\mathrm{HA})$ fractions. When the mutagenic effect was observed only in the highest tested concentrations, the antimutagenic activity was also evaluated. Both mutagenic and antimutagenic assays were performed using T. pallida micronuclei assay. Mutagenicity was observed between different concentrations of the $P$ nitens fractions, EtOAc $(0.460 \mathrm{mg} / \mathrm{mL}), \mathrm{BuOH}(0.142,0.285,0.570$ and $1.14 \mathrm{mg} / \mathrm{mL})$ and HA $(0.050,0.100,0.200$ and $0.400 \mathrm{mg} / \mathrm{mL})$. Whereas the mutagenic effect of the EtOAc fraction was observed in the highest concentration $(0.460 \mathrm{mg} / \mathrm{mL})$, its antimutagenic potential was evaluated. The 0.115 and $0.230 \mathrm{mg} / \mathrm{mL}$ concentrations of the EtOAc fraction demonstrated antimutagenic activity. Based on the results of the present study we can conclude that some $P$. nitens fractions ( $\mathrm{BuOH}$ and $\mathrm{HA}$ ) demonstrated mutagenic effects whereas the EtOAc fraction shown low mutagenicity and amtimutagenicity in the two higher concentrations. Those results stimulate the studies with $P$. nitens, which possess spread geographic distribution and it is still low studied.
\end{abstract}

Keywords: Pterogyne nitens, Leguminosae, mutagenicity, antimutagenicity, Tradescantia pallida. 


\section{INTRODUÇÃO}

Pterogyne nitens Tulasne (Leguminosae Caesalpinioideae) é a única espécie do gênero, sendo popularmente conhecida como "amendoim-do-campo", "amendoim-bravo", "bálsamo", "yvi-raró", "cocal", "tipa", "amendoinzeiro" (Bukart, 1952; Lorenzi, 2000). Essa espécie habita o Cerrado, Caatinga e Mata Atlântica e encontra-se sob risco de extinção, fazendo parte da lista de espécies arbóreas recomendadas para conservação genética no Estado de São Paulo (Do Nascimento et al., 2006). A literatura revela poucos dados etnobiológicos desta leguminosa, destacando-se o seu emprego na tinturaria, construção civil (Carvalho, 1994) e sua ação anti-helmíntica contra Ascaris lumbricoides (Crivos et al., 2007). Estudos fitoquímicos prévios isolaram flavonas e alcalóides guanidino-terpênicos com ação citotóxica sobre linhagens mutantes de Saccharomyces cerevisiae e células de ovário de hamster (Bolzani et al., 1995).

O número de evidencias relatando os efeitos biológicos dos extratos de plantas esta constantemente aumentando. A composição desses extratos naturais que aparentemente exibem apenas propriedades benéficas inclui componentes químicos com atividades mutagênicas, teratogênicas e/ou carcionogênicas. Se os componentes genotóxicos estão presentes, eles podem intercalar-se com a molécula de DNA levando á danos genéticos em regiões de fundamental importância para o controle do ciclo celular e apoptose, acelerando o processo neoplásico. Dessa forma, é muito importante a inclusão da abordagem genotóxica em avaliações toxicológicas dos compostos terapêuticos (Santos et al., 2008). No contexto da bioprospecção que visa à busca de metabólitos bioativos a partir de plantas presentes nos remanescentes do Cerrado e Mata Atlântica do Estado de São Paulo, foram iniciadas as avaliações de mutagenicidade de três espécies vegetais presente nesses biomas, Cryptocaria moschata, C. mandioccana (Lauraceae) e P. nitens. Dentre as espécies avaliadas, o extrato etanólico das folhas de $P$. nitens exibiu ação mutagênica pelo ensaio de micronúcleo em Tradescantia pallida (Oliveira et al., 2007).

$\mathrm{O}$ teste de micronúcleo em Tradescantia pallida (Trad-MCN) é um dos bioensaios mais usados para o rastreamento de efeitos mutagênicos (Klumpp et al., 2004) e recentemente também vem sendo usado para detecção de efeitos antimutagênicos (Flores et al., 2003). Ele é baseado na formação de micronúcleos resultantes da quebra de cromossomos em células mãe de grão de pólen (Klumpp et al., 2004, Valadares et al., 2007).

Considerando a ausência de informações sobre a planta e o seu potencial uso e ampla distribuição, estudos que ampliem os conhecimentos sobre os efeitos dos seus constituintes podem contribuir significativamente para a detecção de metabólitos bioativos de interesse para o desenvolvimento de novos medicamentos. Sendo assim, o presente estudo teve por objetivo avaliar a atividade mutagênica das frações acetato de etila, $n$-butanólica e hidroalcóolica obtidas do extrato etanólico das folhas de P. nitens. O potencial antimutagênico da fração AcOEt (que apresentou efeito mutagênico em concentração muito elevada) também foi avaliado.

\section{MATERIAL E MÉTODOS}

\section{Material vegetal}

As folhas foram coletadas no Instituto de Botânica, São Paulo-SP no mês de abril de 2003, pela Dra. Maria Cláudia Marx Young. O material foi identificado como sendo Pterogyne nitens Tul. (Leguminosae - Caesalpinioideae) pela Dra. Inês Cordeiro do mesmo Instituto. Uma exsicata (SP204319) encontra-se depositada no herbário "Maria Eneida P. Kaufmann" do Instituto de Botânica, São Paulo-SP.

\section{Extração e isolamento}

As folhas de $P$. nitens $(2,8 \mathrm{~kg})$ foram secas à temperatura ambiente e ao abrigo da luz durante 25 dias, sendo posteriormente submetidas à trituração em moinho de facas. $\mathrm{O}$ pó obtido foi levado à maceração empregando $n$-hexano (5L x 5 durante cinco semanas) e com posterior remaceração em etanol ( $7 \mathrm{~L}$ x 5 durante quatro semanas). Os extratos $n$-hexânico e etanólico foram concentrados em evaporador rotatório sob pressão reduzida $\left(<40{ }^{\circ} \mathrm{C}\right)$, rendendo $3,9 \mathrm{~g}(0,14 \%)$ e $12,7 \mathrm{~g}(0,45 \%)$, respectivamente.

O extrato etanólico $(12,5 \mathrm{~g})$ foi dissolvido em 0,8 L de uma mistura de metanol: água (4:1) e então submetido à partição líquido-líquido com de acetato de etila e $n$-butanol 1,0 L (3 x). As frações acetato de etila (AcOEt), $n$-butanólica $(\mathrm{BuOH})$ e hidroalcoólica (HA) foram concentradas em evaporador rotatório sob pressão reduzida $\left(<40{ }^{\circ} \mathrm{C}\right)$, rendendo $2,8 \mathrm{~g}(23 \%), 7,0 \mathrm{~g}$ $(57 \%)$ e $2,3 \mathrm{~g}(20 \%)$, respectivamente.

Uma alíquota de $1,5 \mathrm{~g}$ das frações $\mathrm{BuOH} \mathrm{e}$ HA foram submetidas separadamente a cromatografia "flash" em coluna de gel de sílica da Merck ${ }^{\circledR}(22$ x 4 cm), eluídas em modo gradiente $\left(\mathrm{CHCl}_{3}: \mathrm{MeOH}, 100\right.$ à $\left.50 \%\right)$ fornecendo 25 subfrações de $8 \mathrm{~mL}$. As subfrações foram reunidas por meio da análise em CCDA desenvolvidas em $\mathrm{CHCl}_{3}: \mathrm{MeOH}(4: 1)$ e reveladas através de inspeção no UV (254 e $365 \mathrm{~nm}$ ), anisaldeído-sulfúrico e Reagente de Sakaguchi (Weber, 1930) e nomeadas de BuOH-1 BuOH-7 e HA-1 - HA-8.

As subfrações BuOH-3 e HA-4 forneceram $83 \mathrm{mg}(5,5 \%)$ e $54 \mathrm{mg}$ (3,6\%) da substância 1, enquanto as subfrações BuOH-5 e HA-6 renderam $102 \mathrm{mg}(6,8$ \%) e $39 \mathrm{mg}(2,6 \%)$ da substância 2 , respectivamente. A análise dos espectros de $\mathrm{RMN}$ de ${ }^{1} \mathrm{H}$ e $\mathrm{RMN}$ de ${ }^{13} \mathrm{C}$, bem como a comparação desses com dados da literatura 
permitiu identificar as substâncias 1 e $\mathbf{2}$ como sendo pteroginina e pteroginidina, respectivamente (Corral et al., 1969; Bolzani et al., 1995).

\section{Ensaio de mutagenicidade}

As frações AcOEt e BuOH foram solubilizadas em DMSO $3 \%$ e a fração HA em água destilada. As concentrações das frações foram estabelecidas em relação aos seus rendimentos obtidos por partição líquido-líquido, a partir do extrato etanólico de P. nitens. Assim, as concentrações das frações foram calculadas pela proporção das concentrações obtidas no ensaio de mutagenicidade do extrato etanólico de P. nitens $(0.130$, $0.250,0.500,1.00$ e $2.00 \mathrm{mg} / \mathrm{mL}$ ) (Oliveira et al., 2007). Dessa forma, para a fração AcOEt $(23 \%$ do extrato etanólico) as concentrações testadas foram $0.030,0.058$, $0.115,0.230$ e $0.460 \mathrm{mg} / \mathrm{mL}$; para a fração $\mathrm{BuOH}(57 \%$ do extrato etanólico) as concentrações testadas foram $0.074,0.142,0.285,0.570$ e $1.14 \mathrm{mg} / \mathrm{mL}$, e para a fração HA ( $20 \%$ do extrato etanólico) as concentrações testadas foram: $0.026,0.050,0.100,0.200$ e $0.400 \mathrm{mg} /$ $\mathrm{mL}$.

As inflorescências de Tradescantia pallida ( $T$. pallida) foram coletadas no Horto de Plantas Medicinais da Faculdade de Ciências Farmacêuticas (UNESPAraraquara), distante $4,5 \mathrm{Km}$ do centro de poluição automotiva. Foram utilizadas 20 hastes de 6 a $8 \mathrm{~cm}$ de comprimento, por grupo tratado, nas quais continham as inflorescências. Após coleta, as hastes de T. pallida foram submetidas à fase de adaptação em solução de Hoagland (Roth, 1964) sob aeração constante durante 24 horas. Após o término desse período, as hastes que floresceram foram eliminadas, uma vez que estariam em estágio de divisão avançado, o que impossibilita a observação das tétrades. As hastes remanescentes foram separadas em 8 grupos quando as frações foram solubilizadas em DMSO 3\% (AcOEt e $\mathrm{BuOH})$ sendo eles: Hoagland controle negativo, formol $1,000 \mathrm{ppm}$ - controle positivo, DMSO 3\% - controle de veículo e 5 grupos teste para cada uma das concentrações avaliadas. A solução de formaldeído $1.000 \mathrm{ppm}$ foi utilizada como controle positivo por ser capaz de induzir grande freqüência de micronúcleos em T. pallida (Batalha et al., 1999). Para a fração HÁ (solúvel em água) foram separados 7 grupos: controle negativo e positivo (similar aos citados acima) e 5 grupos teste para as concentrações avaliadas. Os grupos foram tratados durante 8 horas e, em seguida, as hastes foram colocadas em solução de Hoagland por 24 horas, para recuperação pós-tratamento. Após esse período, as inflorescências foram removidas e fixadas em etanol:ácido acético (3:1) por 24 a 48 horas à temperatura ambiente, seguida de armazenamento em etanol $70 \%$ sob refrigeração. As anteras onde se encontravam as tétrades foram maceradas em lâminas com Acetoarmim (0.67\%), cobertas com lamínula e aquecidas à temperatura cerca de $80{ }^{\circ} \mathrm{C}$. A contagem do número de micronúcleos (\%) foi realizada em 300 tétrades por tratamento que continham, em média, $10 \mathrm{ou}$ mais hastes. A elevada freqüência de micronúcleos foi considerada diretamente proporcional a mutagenicidade dos extratos avaliados (Ma, 1983).

\section{Ensaio de antimutagenicidade}

A fração AcOEt foi selecionada para a realização do ensaio de antimutagenicidade, uma vez que não foi observado efeito mutagênico nas menores concentrações. A coleta das inflorescências e os procedimentos metodológicos foram realizados conforme descrito no ensaio de mutagenicidade. Entretanto, para esse ensaio protetor, após o período de adaptação ( 24 horas) em solução de Hoagland, as hastes foram submetidas ao tratamento, com as concentrações da fração AcOEt que não apresentaram efeito mutagênico $(0.030,0.058$, 0.115 e $0.230 \mathrm{mg} / \mathrm{mL}$ ) durante 4 horas. Em seguida, as hastes foram submetidas a tratamento com formol 10.000 ppm durante 4 horas (Batalha et al., 1999). Como controle positivo, inflorescências foram tratadas com solução de Hoagland (4 horas) e de formol 10.000 ppm (4 horas), como controle negativo o tratamento foi realizado com solução de Hoagland (8 horas) e como controle de veículo, as inflorescências foram tratadas com uma solução de DMSO 3\% (4 horas), seguido de mais 4 horas de tratamento com formol $10.000 \mathrm{ppm}$. Para os grupos teste e controle, após o tratamento, as inflorescências foram deixadas em solução de Hoagland por 24 horas (período de recuperação), submetidas à fixação e contagem conforme o procedimento adotado para o ensaio de mutagenicidade.

\section{Análise estatística}

A avaliação estatística foi realizada através da análise da freqüência absoluta de micronúcleos em células mãe do grão de pólen. Os experimentos de mutagenicidade com as frações AcOEt, $\mathrm{BuOH}$ e HA, foram avaliados segundo o teste de normalidade (Shapiro-Wilk) e de homocedasticidade. Observou-se que estas frações não apresentaram distribuição normal, por isso utilizou-se o teste não paramétrico de MannWhitney com a finalidade de comparar todos os grupos com o controle negativo. Para a análise estatística dos resultados do ensaio de antimutagenicidade, os resultados da freqüência de micronúcleos foram comparados com o controle positivo (avaliação do efeito protetor frente ao agente indutor de danos de DNA) e apresentaram distribuição normal. Por essa razão foi aplicado Teste $\mathrm{T}$ para dados amostrais de amostras independentes unilateral. O nível de significância adotado foi de $5 \%$ e a análise estatística dos resultados obtidos foi realizada com o auxílio do programa estatístico BioEstat 4.0 (Belém-PA, Brasil). 


\section{RESULTADOS}

Os resultados da avaliação de mutagenicidade das frações AcOEt, $\mathrm{BuOH}$ e $\mathrm{HA}$ de $P$. nitens estão demonstrados na figura 1 . Os controles veículos (CV) não apresentaram diferença estatística em relação aos controles negativos $(\mathrm{CN})$ excluindo, portanto, a possibilidade de falsos positivos para o efeito mutagênico das frações que foram solubilizadas com este veículo.

Os resultados dos ensaios com a fração AcOEt (figura 1A) mostraram a seguinte relação de média da freqüência de micronúcleos $(\mathrm{M})$ e erro padrão (EP) $(\mathrm{M} \pm \mathrm{EP}): \mathrm{CP}=2.49 \pm 0.29, \mathrm{CN}=0.71 \pm 0.12, \mathrm{CV}$ $=1.06 \pm 0.18,0.030 \mathrm{mg} / \mathrm{mL}=0.82 \pm 0.31,0.058 \mathrm{mg} /$ $\mathrm{mL}=1.17 \pm 0.32,0.115 \mathrm{mg} / \mathrm{mL}=1.17 \pm 0.24,0.230$ $\mathrm{mg} / \mathrm{mL}=1.06 \pm 0.26$, e $0.460 \mathrm{mg} / \mathrm{mL}=1.51 \pm 0.28$. Com os resultados apresentados observamos atividade mutagênica na concentração de $0.460 \mathrm{mg} / \mathrm{mL}$ ( $\mathrm{p}<$ 0.050 ), não sendo observado a mesma atividade nas concentrações menores $(0.030,0.058,0.115,0.23 \mathrm{mg} /$ $\mathrm{mL}$ ). Na fração BuOH (Figura 1B) obtivemos a seguinte relação de média da freqüência de micronúcleos $(\mathrm{M})$ e erro padrão $(\mathrm{EP})(\mathrm{M} \pm \mathrm{EP})$ : $\mathrm{CP}=2.46 \pm 0.25, \mathrm{CN}=$ $0.90 \pm 0.15, \mathrm{CV}=1.10 \pm 0.19,0.074 \mathrm{mg} / \mathrm{mL}=1.27 \pm$ $0.18,0.142 \mathrm{mg} / \mathrm{mL}=1.77 \pm 0.27,0.285 \mathrm{mg} / \mathrm{mL}=1.73 \pm$ $0.31,0.570 \mathrm{mg} / \mathrm{mL}=1.80 \pm 0.34$, e $1.14 \mathrm{mg} / \mathrm{mL}=2.03$ \pm 0.23 . Com os resultados apresentados observamos atividade mutagênica nas concentrações de $0.142 \mathrm{mg} /$ $\mathrm{mL}$ ( $\mathrm{p}<0.050), 0.285 \mathrm{mg} / \mathrm{mL}(\mathrm{p}<0.050), 0.570 \mathrm{mg} / \mathrm{mL}$ $(p<0.050)$ e $1.14 \mathrm{mg} / \mathrm{mL}(\mathrm{p}<0.001)$. Na avaliação da fração HA foi observado a seguinte relação de média da freqüência de micronúcleos $(\mathrm{M})$ e erro padrão (EP) (M $\pm \mathrm{EP}): \mathrm{CP}=1.90 \pm 0.36, \mathrm{CN}=0.75 \pm 0.25,0.026 \mathrm{mg} /$ $\mathrm{mL}=1.13 \pm 0.12,0.050 \mathrm{mg} / \mathrm{mL}=1.53 \pm 0.19,0.100$ $\mathrm{mg} / \mathrm{mL}=2.20 \pm 0.34,0.200 \mathrm{mg} / \mathrm{mL}=2.30 \pm 0.24$, e $0.400 \mathrm{mg} / \mathrm{mL}=3.80 \pm 0.27$. Essa fração apresentou efeito mutagênico nas concentrações de $0.050 \mathrm{mg} / \mathrm{mL}$ $(\mathrm{p}<0.050), 0.100 \mathrm{mg} / \mathrm{mL}(\mathrm{p}<0.010), 0.200 \mathrm{mg} / \mathrm{mL}(\mathrm{p}<$ $0.010)$ e $0.400 \mathrm{mg} / \mathrm{mL}(\mathrm{p}<0.001)$.

Após a realização dos ensaios de mutagenicidade das frações de P. nitens em T. pallida e observada ausência de mutagenicidade na fração AcOEt nas concentrações $0.030,0.058,0.115,0.230 \mathrm{mg} / \mathrm{mL}$, esta fração foi selecionada para ensaios de antimutagenicidade (Figura 2). Os resultados mostraram a seguinte relação de média da freqüência de micronúcleos $(\mathrm{M})$ e erro padrão (EP) $(\mathrm{M} \pm \mathrm{EP}): \mathrm{CP}=2.00 \pm 0.20, \mathrm{CN}=0.77 \pm 0.22$, $\mathrm{CV}=1.87 \pm 0.16,0.030 \mathrm{mg} / \mathrm{mL}=1.63 \pm 0.21,0.058$ $\mathrm{mg} / \mathrm{mL}=1.67 \pm 0.17,0.115 \mathrm{mg} / \mathrm{mL}=1.40 \pm 0.16$, e $0.230 \mathrm{mg} / \mathrm{mL}=1.30 \pm 0.18$. É possível observar que não houve diferença na freqüência de micronúcleos entre o controle positivo e o controle de veículo $(\mathrm{P}=$ $0.304, p>0.050$ ), demonstrando que o veículo não se configura como um agente antimutagênico e, portanto não possui propriedades capazes de interferir no bioensaio. Adicionalmente, uma diferença significativa foi observada entre o controle positivo e o controle negativo $(p<0.001)$. Na comparação entre o controle positivo e as diferentes concentrações, foi observada diferença significativa entre o controle positivo e os tratamentos com 0.115 ( $\mathrm{p}<0.050)$ e $0.230 \mathrm{mg} / \mathrm{mL}$ ( $\mathrm{p}<$ 0.010 ), indicando que nessas concentrações a fração AcOEt de $P$. nitens demonstrou potencial atividade antimutagênico.

Paralelamente aos ensaios biológicos, o estudo químico das frações $\mathrm{BuOH}$ e $\mathrm{HA}$, tendo gel de sílica como suporte cromatográfico, culminou no isolamento dos alcalóides guanidínicos 1 e 2 (Figura 3), previamente descritos como pertencentes ao metaboloma de P. nitens (Bolzani et al., 1995).

\section{DISCUSSÃO}

O estudo de frações ricas em classes de compostos, obtidos de plantas, se faz importante no sentido de realizar estudos biodirecionados, ou seja, que correlacionam à atividade biológica investigada com a classe de substância apresentada na fração. No presente estudo, atividade mutagênica de três diferentes frações de P. nitens (BuOH, AcOEt, HA) foi avaliada através do ensaio de Trad-MCN. Atualmente, o bioensaio de TradMCN tem sido utilizado como ferramenta para avaliar a interação de compostos com o DNA, tornando-se um importante bioindicador de riscos à saúde humana (Carvalho-Oliveira et al., 2005).

$\mathrm{O}$ presente estudo concluiu que as frações $\mathrm{BuOH}$ e HA de $P$. nitens apresentaram ação mutagênica, podendo esta ser atribuída a presença dos alcalóides guanidino-terpênicos, pteroginina (1) e pteroginidina (2) nessas frações (Figura 3), demonstrado através da avaliação fitoquímica (Fernandes et al., 2008). Estudos prévios demonstraram que os alcalóides são capazes de induzir aberrações cromossômicas em linhagem celular CHO (chinese hamster ovary) (Sasaki et al., 1992), mutagenicidade em células pulmonares de hamster chinês (CHL) (Nakayasy et al., 1983); induzem mudanças em cromátides irmãs de linfócitos periféricos humanos (Madle et al., 1981); e aumentam a freqüência de micronúcleo e alterações em cromátides irmãs em células meristemáticas de Allium cepa (Hazen \& Gutiérrez-Gonzálvez, 1988). Ainda na fração HA foi isolado um ciclitol. O mio-inositol é o mais importante ciclitol descrito, sendo que os seus derivados participam da biossíntese de alguns mensageiros secundários associados com a proliferação celular, crescimento celular, eventos de inflamação celular, secreções e outros (Schedler \& Baker, 2004). O inositol hexafosfato (IP ${ }_{6}$ ) é um outro ciclitol para o qual tem sido demonstrada uma potente ação anticâncer, tanto em testes in vivo quanto in vitro (Vucenik \& Shamsuddin, 2003).

A presença de potencial efeito mutagênico das frações $\mathrm{BuOH}$ e $\mathrm{HA}$ alerta para o seu potencial ação anticarcinogênica, em concentrações que possam 

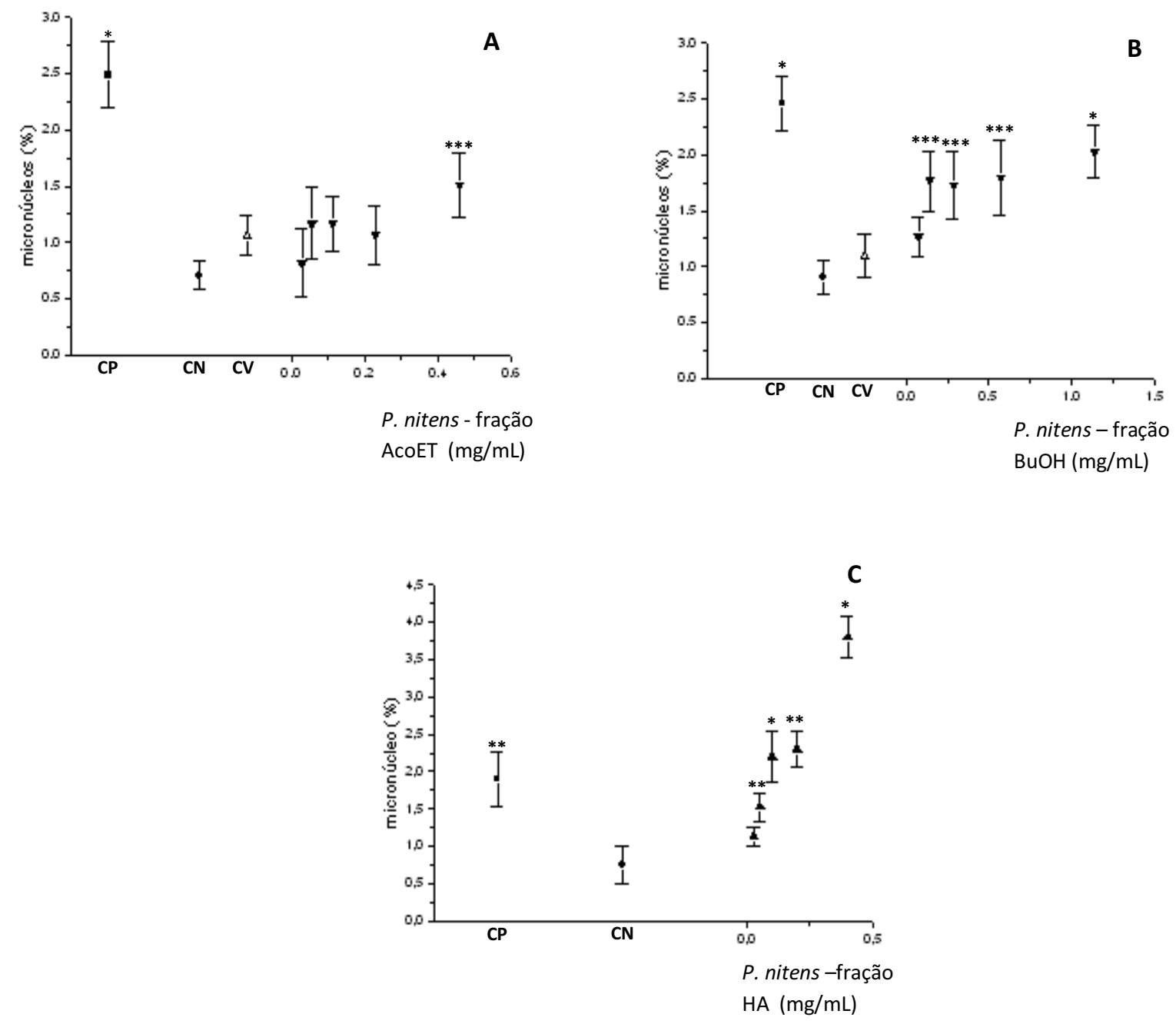

Figura 1. Porcentagem de micronúcleos apresentada para a avaliação do efeito mutagênico da fração avaliadas. A) acetato de etila $(0.058,0.115,0.230$ e $0.460 \mathrm{mg} / \mathrm{mL})$; Mann-Whitney: * controle negativo versus controle positivo $(\mathrm{p}<0.001)$ e $* * *$ controle negativo versus $0.460 \mathrm{mg} / \mathrm{mL}(\mathrm{p}<0.050)$. B) Fração butanólica $(0.074,0.142,0.285,0.570,1.14 \mathrm{mg} / \mathrm{mL})$; Mann-Whitney: * controle negativo versus controle positivo $(\mathrm{p}<0.001)$; *** controle negativo versus $0.142 \mathrm{mg} / \mathrm{mL}(\mathrm{p}<0.050), 0.285 \mathrm{mg} / \mathrm{mL}$ $(\mathrm{p}<0.050), 0.570 \mathrm{mg} / \mathrm{mL}(\mathrm{p}<0.050)$ e $1.14 \mathrm{mg} / \mathrm{mL}(\mathrm{p}<0.001)$. C) Fração hidroalcóolica $(0.026,0.050,0.100,0.200$ e 0.400 $\mathrm{mg} / \mathrm{mL})$; Mann-Whitney: *controle negativo versus controle positivo $(\mathrm{p}<0.050)$, ***controle negativo versus $0.050 \mathrm{mg} / \mathrm{mL}$ $(\mathrm{p}<0.050), 0.100 \mathrm{mg} / \mathrm{mL}(\mathrm{p}<0.010), 0.200 \mathrm{mg} / \mathrm{mL}(\mathrm{p}<0.010)$ e $0.400 \mathrm{mg} / \mathrm{mL}(\mathrm{p}<0.001)$. ( $(\bullet)$ Controle positivo, $(\bullet)$ controle negativo, $(\boldsymbol{\Delta})$ controle de veículo, $(\boldsymbol{\nabla})$ tratamentos com as frações de P.nitens. $*(p<0.001), * *(p<0.010)$ e $* * *(p<0.050)$.

assegurar seu uso sem induzir mutagenicidade nas células normais. Mutações que acarretem, por exemplo, modificações na expressão do gene p53 ou deleção do gene que codifica $\mathrm{pRb}$ podem aumentar a sensibilidade de células tumorais malignas a agentes quimioterápicos (Hochhauser, 1997). Diversos estudos vêm sendo conduzidos para a utilização de drogas que tenham como mecanismo de ação a ligação ao DNA (aductos) ou que se intercalem seletivamente neste, induzindo sinais intracelulares que levem as células tumorais a apoptose (Havelka et al., 2007; Wheate et al., 2007). A vincristina, e a camptotecina são alcalóides naturais, que vêm sendo utilizados na oncologia por interferir na organização de microtúbulos e inibir a topoisomerase I respectivamente (Costa et al., 2008, Sirikantaramas et al., 2007).

Um recente estudo fitoquímico das folhas de $P$. nitens, revelou um grande acúmulo de 7-metoxiflavonas na fração AcOEt (Fernandes et al., 2008). Os resultados obtidos demonstram que a fração AcOEt exibiu mutagenicidade a $0,460 \mathrm{mg} / \mathrm{mL}$. De fato, a literatura descreve que flavonóides possuem a capacidade de intercalar-se às moléculas de DNA em determinadas concentrações, sendo algumas vezes utilizados como coadjuvantes na terapia antineoplásica (Ferguson \& Denny, 2007). Ao avaliar as concentrações não 


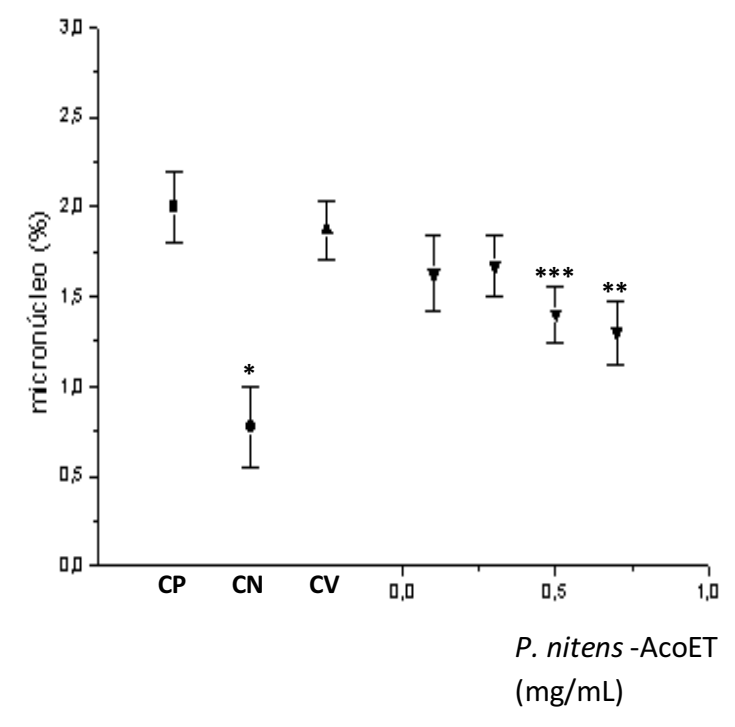

Figura 2. Porcentagem de micronúcleo apresentado no teste de micronúcleo em Tradescantia pallida para a avaliação do efeito antimutagênico da fração acetato de etila de Pterogyne nitens, nas concentrações de 0.030, 0.058, 0.115 e $0.230 \mathrm{mg} / \mathrm{mL}$. Teste $\mathrm{T}$ : dados amostrais para amostras independentes (unilateral)-controle positivo versus controle negativo $(\mathrm{p}<0.001)$, controle positivo versus $0.115 \mathrm{mg} /$ $\mathrm{mL}(\mathrm{p}<0.050)$ e controle positivo versus $0.230 \mathrm{mg} / \mathrm{mL}$ $(\mathrm{p}<0.010)$. (घ) Controle positivo, (•) controle negativo, ( $\boldsymbol{\Delta})$ controle de veículo, ( $\boldsymbol{\nabla})$ tratamentos com a fração acetato de etila de P. nitens. * $(\mathrm{p}<0.001), * *(\mathrm{p}<0.010)$ e $* * *(\mathrm{p}<0.050)$.<smiles>CC(C)=CCN(CC=C(C)C)C(=N)N</smiles><smiles>CC(C)=CCNC(=N)NCC=C(C)C</smiles>

Figura 3. Alcalóides guanidínicos $\mathbf{1}$ e $\mathbf{2}$ isolados das frações n-butanólica e hidroalcoólica de Pterogyne nitens.

mutagênicas desta fração observamos que algumas delas apresentaram atividade antimutagênica $(0,115$ e $0,230 \mathrm{mg} / \mathrm{mL}$ ). A atividade protetora ao DNA pode estar associada ao fato de que as flavonas apresentam grupos fenóis que lhes conferem uma ação antioxidante (conjugando as enzimas com as glutationas transferases e glucoronosiltransferase), agindo como potenciais agentes antimutagênicos (Fernandes et al., 2008; Van der Merwe et al., 2006; Snijman et al., 2007).

Considerando que a fração AcOEt não causa danos no DNA, os resultados descritos no presente estudo sugerem que a ação mutagênica observada no extrato etanólico de $P$. nitens descrito anteriormente na literatura (Oliveira et al., 2007) pode ser atribuída em grande parte aos constituintes químicos presentes nas frações $\mathrm{BuOH}$ e $\mathrm{HA}$.
Nas Figuras 1B e 2 é possível observar as atividades mutagênica e antimutagênica da fração AcOEt. Compostos que apresentam tanto características mutagênicas como antimutagênicas são conhecidos como compostos de Janus (Zeiger, 2003). Prévios estudos descrevem compostos com a mesma característica, como é o caso dos $\beta$-carotenos e ácido ascórbico (Kaya et al., 2002; Paolini et al., 2003). Ainda na Figura 2 é possível observar a atividade antimutagênica da AcOEt somente nas maiores concentrações. Resultados semelhantes foram encontrados por Kaur et al. (2002) ao demonstrar o efeito antimutagênico das frações acetona e metanólica de Terminalia arjuna utilizando o teste de Ames para este fim.

A descrição do potencial mutagênico e antimutagênico das frações AcOEt, $\mathrm{BuOH}$ e $\mathrm{HA}$ é de grande valia, considerando-se que a madeira de $P$. nitens vem sendo empregada indiscriminadamente pela construção civil e, por tratar-se de uma leguminosa pertencente a um gênero monoespecífico, informações biológicas e químicas são úteis para o uso sustentável de uma espécie que está seriamente ameaçada de extinção (Carvalho, 1994). Ainda, o potencial anticarcinogênico deve ser futuramente explorado, considerando que as frações $\mathrm{HA}$ e $\mathrm{BuOH}$ demonstraram-se mutagênicos na maioria das concentrações testadas.

\section{AGRADECIMENTOS}

Os autores agradecem à FAPESP (processos n- 06/60891-2 e 03/00886-7), Biota/FAPESP (Instituto Virtual da Biodiversidade, processo $\mathrm{n}^{\circ}$ 03/021767), BIOprospecTA/FAPESP (processo $\mathrm{n}^{\circ}$ 04/079327), CNPq e CAPES pelos auxílios concedidos. Agradecemos ainda ao Prof. Dr. Luis Vitor Silva do Sacramento do Departamento de Princípios Ativos Naturais e Toxicologia da Faculdade de Ciências Farmacêuticas-UNESP, responsável pelo cultivo da Tradescantia pallida no Horto da mesma faculdade.

\section{REFERÊNCIAS}

Batalha JRF, Guimarães ET, Lobo DJA, Lichtenfels AJFC, Deur T, Carvalho HA, Alves ES, Domingos M, Rodrigues GS, Saldiva PHN 1999. Exploring the clastogenic effects of air pollutants in São Paulo (Brazil) using the Tradescantia micronuclei assay. Mutat Res 426: 229-232.

Bolzani VS, Gunatilaka AAL, Kingston DGI 1995. Bioactive guanidine alkaloids from Pterogyne nitens. J Nat Prod 58: 1683-1688.

Bukart A 1952. Las Leguminosas Argentinas. Aemé Agengy, Buenos Aires.

Carvalho PER 1994. Espécies florestais brasileiras: recomendações silviculturais, potencialidades e uso da madeira, p. 163.

Carvalho-Oliveira R, Pozo RMK, Lobo DJA, Lichtenfels AJFC, Martins-Junior HÁ, Bustilho JOWV, Saiki M, Sato IM, Saldiva PHN, 2005. Diesel emissions 
significantly influence composition and mutagenicity of ambient particles: a case study in São Paulo, Brazil. Environ Res 98: 1-7.

Corral RA, Orazi OO, Petruccelli MF 1969. Guanidine alkaloids of Pterogyne nitens. Experientia 25: 10201021.

Costa MM, Hilliou F, Duarte P, Pereira LG, Almeida I, Leech M, Memelink J, Barcelo AR, Sottomayor M 2008. Molecular cloning and characterization of a vacuolar class III peroxidase involved in the metabolismo of anticancer alkaloids in Catharanthus roseus. Plant Physiol 146: 403-417.

Crivos M, Martinez MR, Pochettino ML, Remorini C, Sy A, Teves L 2007. Pathways as "signatures in landscape": Towards an ethnography of mobility among the Mbya-Guaraní (Northeastern Argentina). J Ethnobiol Ethnomed 3: 2.

Do Nascimento WMO, Cruz ED, Moraes MHD, Menten JOM 2006. Qualidade sanitária e germinação de sementes de Pterogyne nitens Tull. (LeguminosaeCaesalpinioideae). Rev Bras Sementes 28: 149-153.

Ferguson LR, Denny WA 2007. Genotoxicity of non-covalent interactions: DNA intercalators. Mutat Res 623: 1423.

Fernandes DC, Regasini LO, Vellosa JCR, Pauletti PM, Castro-Gamboa I, Bolzani VS, Oliveira OMM, Silva DHS 2008. Myeloperoxidase inhibitory and radical scavenging activities of flavones from Pterogyne nitens. Chem Pharm Bull 56: 723-726.

Flores LER, Madrigal-Bujaidar E, Salazar M, Chamorr G 2003. Anticlastogenic effect of Spirulina maxima extract on the micronuclei induced by maleic hydrazide in Tradescantia. Life Sci 72: 1345-1351.

Havelka AM, Berndtsson M, Olofsson MH, Shoshan MC, Linder S 2007. Mechanisms of action of DNA-damaging anticancer drugs in treatment of carcinomas: is acute apoptosis an "off-target" effect?. Mini Rev Med Chem 7: 1035-1039.

Hazen MJ, Gutiérrez-Gonzálvez MG 1988. UV-mediated toxic bioactivity of harmine in the meristematic cells of Allium cepa. Mutagenesis 3: 333-337.

Hochhauser D 1997. Modulation of chemical chemosensitivity through altered expression of cell cycle regulatory genes in cancer. Anticancer Drug 8: 903-910.

Kaya B, Creus A, Velazquez A, Yanikoglu A, Marcos R 2002. Genotoxicity is modulated by ascorbic acid: studies using the wing spot test in Drosophila. Mutat Res 520: 93-101.

Kaur K, Arora S, Kumar S, Nagpal A 2002. Antimutagenic activities of acetone and methanol fractions of Terminalia arjuna. Food Chem Toxicol 40: 14751482.

Klumpp A, Ansel W, Fomim A, Schnirring S, Pickl C 2004. Influence of climatic condition the mutations in pollen mother cells of Tradescantia clone 4430 and implications for the Trad-MCN bioassay protocol. Hereditas 141: 142-148.

Lorenzi H 2000. Arvóres brasileiras: Manual de Identificação e Cultivo de Plantas Arbóreas Nativas do Brasil. $3^{\mathrm{a} e d .}$. Instituto Plantarum de Estudos da Flora, 01:163.

Ma TH 1983. Tradescantia micronucleus (Trad-MCN) test for environmental clastogens. In: Kolber, Wong, Dewoskin \& Hughes (Eds.). In vitro toxicity testing of environmental agents. Plenium Publishing Cooporation, Macomb, 191-214.

Madle E, Obe G, Hansen J, Ristow H 1981. Harman and norharmane: induction of sister-chromatid exchanges in human peripheral lymphocytes in vitro and interaction with isolated DNA, Mutat Res 90: 433-442.

Nakayasy M, Nakasato F, Sakamoto H, Terada M, Sugimura T 1983. Mutagenic activity of norharman and Harman in Chinese lung cells in assay with diphtheria toxin resistance as a marker, Cancer Lett 17: 249-255.

Oliveira AM, Caliri CM, Regasini LO, Talascrea M, Peron MCC, Silva DHS, Santos AG, Bolzani VS, Cabalheiro AJ, Soares CP 2007. Evaluation of micronuclei frequency in Tradescantia pallida pollen mother cells treated with ethanolic extracts isolated from Cryptocarya mandioccana, Cryptocarya moschata and Pterogyne nitens, Rev Bras Toxicol 20: 73-78.

Paolini M, Abdel-Rahman SZ, Sapone A, Pedulli GF, Perocco P, Cantelli-Forti G, Legator MS 2003. Beta-carotene: a cancer chemopreventive agent or a co-carcinogen? Mutat Res 543: 195-200.

Roth I 1964. Microtecnica vegetal. Caracas: Imprenta Universitária, p. 88.

Santos RA, Cabral TR, Cabral IR, Antunes LMG, Andrade CP, Santos PCC, Bahia MO, Pessoa C, Nascimento JLM, Burbano RR, Takahashi CS 2008. Genotoxic effect of Physalis angulata L. (solanaceae) extract on human lymphocytes treated in vitro. Biocell 32: 195-200.

Sasaki YF, Yamada H, Shimoi K, Kinae N, Tomita I, Matsumura H, Ohta T, Shirasu Y 1992. Enhancing effects of heterocyclic amines and $\beta$-carbolines on the induction of chromosome aberrations in culture mammalian cells. Mutat Res 269: 79-95.

Schedler DJA, Baker DC 2004. Fluorinated cyclitols as useful biological probes of phosphatidyeinositol metabolism. Carbohyd Res 339: 1585-1595.

Sirikantaramas S, Asano T, Sudo H, Yamazaki M, Saito K 2007. Camptothecin: therapeutic potential and biotechnology. Curr Pharm Biotechnol 8: 196-202.

Snijman PW, Swanevelder S, Joubert E, Green IR, Gelderblom WCA 2007. The antimutagenic activity of the major flavonoids of rooibos (Aspalathus linearis): Some dose-response effects on mutagen activationflavonoid interactions, Mutat Res 631: 111-123.

Valadares MC, Rezende KR, Pereira ERT, Sousa MC, Gonçalves B, Assis JC, Kato MJ 2007. Protective effects of 4-nerolidylcatechol agaist genotoxicity induced by cyclophosphamide. Food Chem Toxicol 45: 1975-1978.

Van Der Merwe JD, Joubert E, Richards ES, Manley M, Snijman PW, Marnewick JL, Gelderblom WCA 2006. A comparative study on the antimutagenic properties of aqueous extracts of Aspalathus linearis (rooibos), different Cyclopia spp (honeybush) and Camellia sinensis teas. Mutat Res 611: 42-53.

Vucenik I, Shamsuddin AM 2003. Cancer Inhition by inositol hexaphosphate $\left(\mathrm{IP}_{6}\right)$ and inositol: from laboratory to clinic. J Nutr 133: 3778S-3784S.

Weber CJ 1930. A modification of Sakaguchi's reaction for the quantitative determination of arginine. $\mathrm{J} \mathrm{Biol} \mathrm{Chem}$ 86: 217-222.

Wheate NJ, Brodie CR, Collins JG, Kemp S, Aldrich-Wright JR 2007. DNA intercalators in cancer therapy: organic and inorganic drugs and their spectroscopic tools of analysis, Med Chem 7: 627-648.

Zeiger E 2003. Illusions of safety: antimutagens can be mutagens, and anticarcinogens can be carcinogens. Mutat Res 543: 191-194. 